\title{
ASSESSORIA CONTÁBIL COMO FERRAMENTA DE GESTÃO ESTRATÉGICA PARA AS ORGANIZAÇÕES EM TEMPOS DE CRISE
}

\section{ARTIGO ORIGINAL}

MATOS, Amanda de Melo', LIMA, Ana Carolina Carvalho², CUNHA, Brenda Spatola da $^{3}$, CARDOSO, Jhony da Silva ${ }^{4}$, SANTOS, Mônica Ramos dos ${ }^{5}$, ROBERTO, José Carlos Alves ${ }^{6}$, LOPES, Nelânia Ferreira ${ }^{7}$

MATOS, Amanda de Melo. Et al. Assessoria contábil como ferramenta de gestão estratégica para as organizações em tempos de crise. Revista Científica Multidisciplinar Núcleo do Conhecimento. Ano. 06, Ed. 11, Vol. 11, pp. 197-218. Novembro 2021. ISSN: 2448-0959, Link de acesso: https://www.nucleodoconhecimento.com.br/contabilidade/assessoria-contabil, DOI: 10.32749/nucleodoconhecimento.com.br/contabilidade/assessoria-contabil

\section{RESUMO}

Atualmente, são muitas as modificações que ocorreram no setor econômico do Brasil e do mundo. Por isso, nota-se a necessidade de se pesquisar sobre a importância da assessoria contábil em tempos de crise, visto que a contabilidade tem função de auxiliar no fornecimento e planejamento acerca das informações orçamentárias. Um dos principais problemas observados dentro do setor contábil de uma organização é deixar de controlar as contas a pagar e receber e não saber precificar os produtos e/ou serviços de uma empresa. Desse modo, elaborou-se a seguinte questão: De que forma a assessoria contábil pode ser utilizada como uma ferramenta de gestão estratégica para as organizações em tempos de crise?

\footnotetext{
${ }^{1}$ Graduanda do curso de Ciências Contábeis.

${ }^{2}$ Graduanda do curso de Ciências Contábeis.

${ }^{3}$ Graduanda do curso de Ciências Contábeis.

${ }^{4}$ Graduando do curso de Ciências Contábeis.

${ }^{5}$ Graduanda do curso de Ciências Contábeis.

${ }^{6}$ Orientador. Mestre em Engenharia de produção, Especialista Logística empresarial e Graduado em Administração com Ênfase em Marketing.

${ }^{7}$ Orientadora. Especialista em Auditoria Contábil, Financeira e Tributária e Graduada em Ciências Contábeis.
}

RC: 101899

Disponível em: https://www.nucleodoconhecimento.com.br/contabilidade/assessoriacontabil 
Objetivou-se, com a realização desta pesquisa, compreender a importância da assessoria contábil em tempos de crise para a manutenção de uma organização. Diante do exposto, compreendeu-se que a assessoria contábil é de suma importância para uma organização em tempos de crise, visto que é uma ferramenta que auxilia os gestores em todo o processo de planejar, gerenciar, executar, controlar e até mesmo na adoção de decisões. Logo, por meio da assessoria contábil, é possibilitado o conhecimento da situação empresarial, a tomada de decisões auxiliada pelo profissional da contabilidade diante de situações de crise, bem como o controle do orçamento das contas a pagar e receber, o que auxilia na estabilização orçamentária e financeira de uma organização, além de minimizar os efeitos da crise que esta está enfrentando, gerando lucros e o mantimento do negócio.

Palavras-chave: Assessoria contábil, Tempos de crise, Gestão estratégica.

\section{INTRODUÇÃO}

Atualmente, são muitas as modificações que ocorreram no setor econômico do Brasil e do mundo. Por isso, nota-se a necessidade da pesquisa sobre a importância da assessoria contábil em tempos de crise, visto que a contabilidade tem função de auxiliar no fornecimento e planejamento acerca das informações orçamentárias. Ela é uma ferramenta importante para a continuação de um negócio e, também, para a superação da crise que o mesmo enfrenta (CARVALHO, 2010; SANTOS; SOUZA, 2010).

As empresas vêm sofrendo com a ausência de controle orçamentário no âmbito das contas, em relação ao que necessitam pagar e ao que devem receber, e o setor empresarial objetiva a minimização da crise no âmbito financeiro por meio da redução de custos e investimentos, com o intuito de estabilização orçamentária e com o retorno de lucros para o mantimento de seu negócio (TROMBETTA, 2014; SIGNORI, 2013). 
Um dos principais problemas observados dentro do setor contábil de uma organização é deixar de controlar as contas a pagar e receber e não saber precificar produtos e/ou serviços em uma empresa. Outro fator também decorrente da crise do país é a instabilidade política que permeia a nação. Desse modo, elabora-se a seguinte questão: De que forma a assessoria contábil pode ser utilizada como uma ferramenta de gestão estratégica para as organizações em tempos de crise? (TROMBETTA, 2014; BARBOSA FILHO, 2017).

À vista disso, objetiva-se compreender a importância da assessoria contábil em tempos de crise para a manutenção de uma organização (FELIPE, 2017), além de analisar o conceito de contabilidade, seu objeto de estudo e seu campo de aplicação; identificar as atribuições e a importância do profissional da área de contabilidade dentro de uma organização; verificar a situação atual da economia no país e como tem ocorrido a prestação de serviços na área contábil e observar como a contabilidade está sendo aplicada nas áreas administrativas e financeiras.

Diante do exposto, a pesquisa terá como fundamento o procedimento de pesquisa bibliográfica, caracterizado por fontes secundárias, realizando pesquisas em buscadores como: Google Acadêmico e SciELO. A partir da realização desta pesquisa, espera-se a compreensão dos discentes e futuros profissionais da área de Ciências Contábeis acerca da importância da assessoria contábil em tempos de crise, tendo em vista que eles necessitarão ser estrategistas e articuladores para pensarem em diferentes possibilidades em um período de incerteza.

\section{FUNDAMENTAÇÃO TEÓRICA}

De acordo com Carvalho et al. (2019), uma boa fundamentação teórica é resultado de uma criteriosa Revisão Bibliográfica ou de uma Revisão de Literatura, como é chamada por alguns.

RC: 101899

Disponível em: https://www.nucleodoconhecimento.com.br/contabilidade/assessoriacontabil 
Em acordo, Gonçalves (2019) ressalta que os meios de levantamento da literatura são obtidos a partir da disponibilidade de materiais, de forma física ou virtual, para o êxito no desenvolvimento da pesquisa.

\subsection{CONTABILIDADE}

Conforme Santos e Souza (2010), a contabilidade foi observada por muito tempo como um sistema de informações relativas ao tributo. No entanto, atualmente, esse ramo possui um mercado com crescimento ascendente e competitivo.

Ao tratarem da história da contabilidade, Santos e Souza (2010) enfatizam que ela é bastante antiga, assim como a humanidade, e que ela se desenvolve com o passar do tempo e com a evolução do mundo.

Para Ribeiro (2003 apud ÁVILA; BÄCHTOLD; VIEIRA, 2011), a contabilidade é uma ciência que possibilita, através de suas técnicas, o mantimento do controle constante do patrimônio.

Com base em Santos e Souza (2010), nota-se que a contabilidade é uma ferramenta gerencial que auxilia os gestores diante de todo o processo de planejar, gerenciar, executar, controlar e até mesmo na adoção de decisões.

Santos e Almeida (2012) ressaltam que a ciência social aplicada na contabilidade está modificando-se constantemente em diversos ambientes de atuação.

Em consonância, Santos e Souza (2010) expõem que o principal objetivo dessa ciência é o atendimento do público externo e interno, além da busca por informações a serem prestadas para uma atuação de melhor qualidade nos serviços.

Salienta-se ainda, de acordo com Carvalho (2010), que a contabilidade aplicada em diversos setores da sociedade possui normas específicas e conceitos próprios que a regem.

RC: 101899

Disponível em: https://www.nucleodoconhecimento.com.br/contabilidade/assessoria$\underline{\text { contabil }}$ 
Essas normas são apontadas por Haddad e Mota (2010) como princípios gerais da contabilidade. Os princípios gerais estudam, registram, controlam, demonstram o orçamento aprovado e acompanham a sua execução, os atos administrativos etc.

Para Carvalho (2010), a contabilidade tem como objetivo oferecer informações aos usuários. Essas informações devem ser atualizadas, pois estão associadas aos resultados alcançados e às questões relacionadas ao orçamento, patrimônio, decisões etc.

\subsection{PROFISSIONAL DA CONTABILIDADE}

De acordo com as diretrizes de âmbito nacional, o principal objetivo da formação em Ciência Contábeis é a atuação do futuro profissional diante da inclusão de discussões que possibilitem a consciência social e o enfrentamento de problemas (MAZZIONI, 2013).

Para Felipe (2017), compete a esse profissional (fluxograma 1):

Fluxograma 1 - Principais competências de um profissional contábil

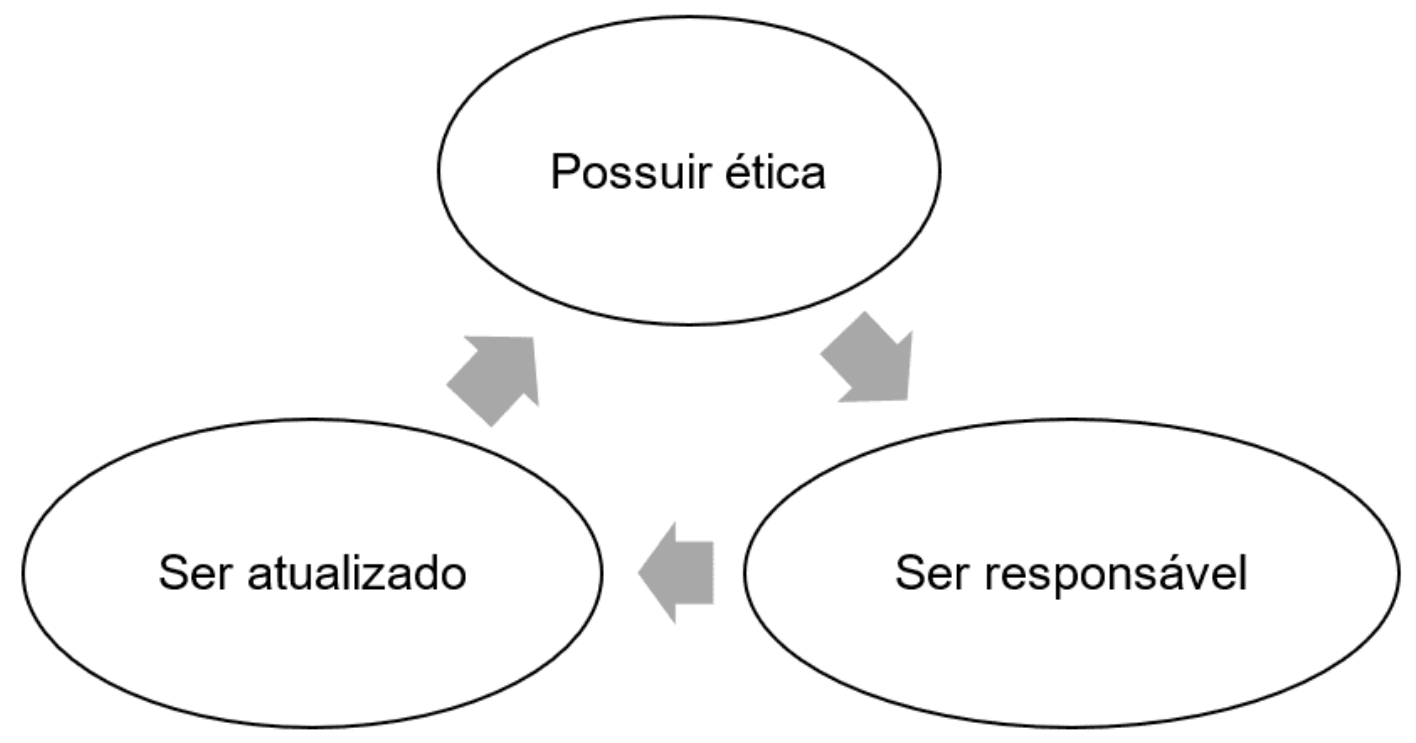

Adaptado de: Felipe (2017, p. 4).

RC: 101899

Disponível em: https://www.nucleodoconhecimento.com.br/contabilidade/assessoriacontabil 
Assim, observa-se o destaque do profissional da área contábil dentro das organizações. Pesquisas foram realizadas, e continuam sendo, para a verificação da realidade da valorização desses profissionais (SANTOS; SOUZA, 2010).

Em acordo, Santos e Souza (2010) apontam que este profissional necessita ser adaptável para aderir ao dever de gerenciar as informações e para utilizar de mecanismos de decisão no âmbito de uma entidade.

Ruschel; Frezza e Utzig (2011) acreditam que o profissional das ciências contábeis é considerado um dos principais pilares da contabilidade, pois transmite informações ao fisco e aos clientes.

De acordo com Mazzioni (2013), as modificações nos perfis dos profissionais dessa área serão refletidas nas instituições formadoras desses profissionais e, por isso, necessitam de um melhor planejamento profissional $e$ interações frente às necessidades do mercado atual.

\subsection{CONCEITO DE ORGANIZAÇÕES}

As organizações são caracterizadas por construírem relações sociais e de produção. Elas encontram-se incluídas em diversos setores essenciais da sociedade e fazem parte das atividades corriqueiras e vitais do ser humano (SCHULTZ, 2016).

Em consonância, Daft (2014) aborda sobre a dificuldade do entendimento acerca das organizações. Entretanto, destaca-se que grande parte da sociedade passa horas exercendo funções dentro de uma organização, seja qual for o tipo.

Para Xavier (2015), as organizações podem ser formais, lucrativas e não lucrativas. As formais são fundamentadas em regras; as lucrativas objetivam ter recursos próprios para que possam se manter e as não lucrativas são direcionadas à sociedade.

RC: 101899

Disponível em: https://www.nucleodoconhecimento.com.br/contabilidade/assessoria$\underline{\text { contabil }}$ 
Vive-se em uma corporação organizacional, na qual as corporações são vitais para o suprimento de todas as necessidades existentes para as populações, sendo, assim, considerada uma ação social (SOUZA, 2012).

\subsubsection{GESTÃO EMPRESARIAL}

Compreende-se 0 conceito de gestão empresarial como uma estratégia organizacional que visa conduzir melhores resultados a todos os âmbitos de uma empresa (MOREIRA, 2018).

Para Penteado et al. (2012), os modelos atuais de gestão estão demonstrando esgotamento, o que dificulta a competição no mercado e a sobrevivência das organizações.

Conforme Becker (2016), uma gestão empresarial de excelência baseia-se nos conhecimentos econômicos e é notada pelos estudos relativos à destinação eficiente dos recursos.

\subsection{DEFINIÇÃO DE CRISE ECONÔMICA}

A crise econômica pode ser conceituada através da obra de Marx (2006 apud TONELO, 2014), "O Capital", lançado pela editora Civilização Brasileira:

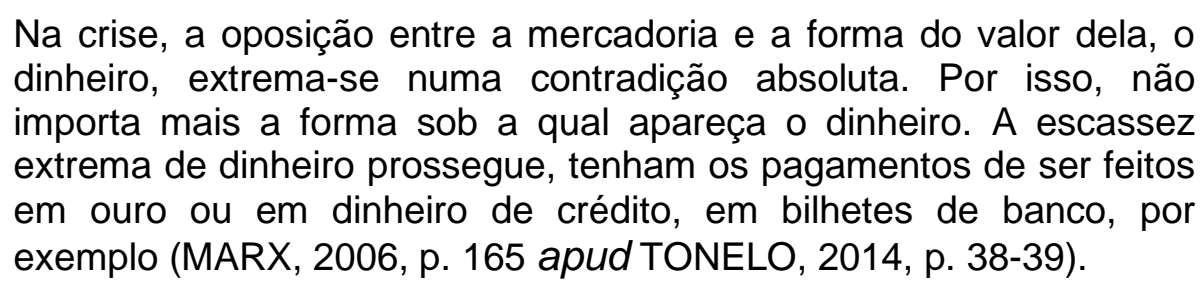

Para Barbosa Filho (2017), a crise econômica define-se através da retração da economia, da redução de lucratividade, do consumo etc. de uma nação, no seu âmbito público e nas corporações privadas.

RC: 101899

Disponível em: https://www.nucleodoconhecimento.com.br/contabilidade/assessoria$\underline{\text { contabil }}$ 
Percebe-se, a partir de Arruda (2017), que a crise econômica é um período de instabilidade financeira, carência nos processos produtivos, no comércio e no consumo em geral.

\subsubsection{CENÁRIO ECONÔMICO DO BRASIL}

A economia brasileira encontra-se em crise desde 2014, quando se observou a queda do produto per capita brasileiro, em cerca de 9\%, entre 2014 e 2016 (BARBOSA FILHO, 2017).

Em acordo, Arruda (2017) expõe que o país enfrenta uma grande crise econômica nos últimos anos, demonstrando aos outros países e à própria nação uma grande instabilidade financeira que pode percorrer por anos.

Para Felipe (2017), a atual situação do Brasil dificulta o pagamento e recebimento de contas de todas as esferas da sociedade. E, assim, nota-se um sistema desafiador e impactante (RUSCHEL; FREZZA; UTZIG, 2011).

\subsubsection{ORIGEM}

A origem da crise econômica brasileira é apontada por Barbosa Filho (2017) como o somatório de erros relativos às políticas públicas, que diminuíram a capacidade de ascensão econômica e ocasionaram um grande custo fiscal desde 2014 (fluxograma 2).

Fluxograma 2 - Origem da crise econômica no território brasileiro

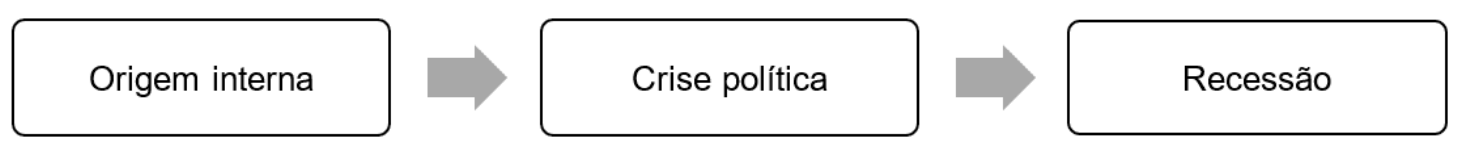

Adaptado de: Barbosa Filho (2017).

RC: 101899

Disponível em: https://www.nucleodoconhecimento.com.br/contabilidade/assessoriacontabil 


\subsubsection{CONSEQUÊNCIAS}

Conforme Barbosa Filho (2017), a crise econômica tem como resultado um conglomerado de choques de oferta e de demanda. Observou-se que as consequências da crise econômica no país têm acometido diversos setores como, por exemplo, os serviços contábeis (FELIPE, 2017).

A crise na economia propicia o agravamento de problemas sociais, a crescente desigualdade no país, a piora na saúde e nos direitos básicos da população (VIEIRA, 2016).

Diante do apresentado, Berselli e Santos (2016) apontam que a crise econômica é expressiva e pode afetar o comércio e a sociedade de modo em geral, com a ausência de empregos, com o fechamento de empreendimentos, redução de vendas etc.

\subsection{A CONTABILIDADE COMO FERRAMENTA DE GESTÃO}

Conforme Felipe (2017), a ciência da contabilidade é importante, pois auxilia na gestão das empresas, mesmo em tempos de crise. Por meio dos competentes e atualizados profissionais, é possível que a organização se desenvolva diante de tomadas de decisões para o sucesso e mantimento do seu negócio.

A contabilidade, como ferramenta da gestão, permite que a organização seja conduzida a partir de missões e objetivos para fins de cumprimento de metas e para fins de êxito no mercado (MOREIRA, 2018).

Destacam-se, ainda, as demonstrações contábeis, como uma forma de gerenciar as informações de uma entidade, de modo que identifiquem as áreas com insucesso e auxiliem na tomada de decisões para o sucesso da empresa (SANTOS; SOUZA, 2010). 
Em vista disso, Santos e Souza (2010) expõem que as informações geradas são recursos primordiais para a definição dos objetivos e para o estabelecimento de estratégias para a expansão dos investimentos e dos resultados organizacionais.

\subsubsection{CONTABILIDADE GERENCIAL}

Segundo Padoveze (2012), a base de conceitos que fundamentam a Contabilidade Gerencial é composta por três elementos: as teorias da mensuração, da decisão e da informação, partes fundamentais de um ramo considerado essencial para todas as entidades.

A Contabilidade Gerencial abrange uma gama de informações e dados de custos, receitas e lucros, que necessitam ser utilizadas e analisadas por gerentes da própria organização (GARRISON; NOREEN; BREWER, 2013).

Dessa forma, Padoveze (2012) expõe que a Contabilidade Gerencial abrange informações necessárias que complementam as informações já existentes no âmbito da Contabilidade Financeira, porém, de forma mais detalhada e analítica.

\subsubsection{CONTABILIDADE FINANCEIRA}

Para Salim e Oliveira (2019), a Contabilidade Financeira tem como base os dados e procedimentos de controle dos demonstrativos fiscais de uma organização. Logo, ela considera somente os processos relativos aos fins monetários.

Com base nisso, Rodrigues (2015) ressalta que essa ramificação da contabilidade é ligada às práticas monetárias, com 0 intuito do reconhecimento total das movimentações em valor e quantidades, determinando a lucratividade ou prejuízo de uma entidade em um determinado período.

RC: 101899

Disponível em: https://www.nucleodoconhecimento.com.br/contabilidade/assessoriacontabil 


\subsubsection{CONTABILIDADE FISCAL}

A Contabilidade Fiscal possui o objetivo de estudar a teoria e aplicar de forma prática os conceitos e normas básicas da contabilidade e da legislação tributária (CREPALDI, 2015).

Em consonância, Giaretta et al. (2020) abordam que a Contabilidade Fiscal tem como principais características certas atividades, como a de receber e lançar notas fiscais, apurar impostos, tributos, entregar arquivos, entre outras.

É destacado por Crepaldi (2015) que o objeto da Contabilidade Fiscal é a apuração de forma exata e clara do resultado econômico do exercício social, através das legislações do IRPJ e da CSLL.

\subsubsection{PLANEJAMENTO ESTRATÉGICO}

Conforme Bruni e Gomes (2010), o planejamento estratégico pode ser conceituado como um sistema reunido de planos operacionais com enfoque no processo estratégico, orçamentário e nos programas, utilizado como forma de estabelecimento de uma organização no mercado.

Em acordo, Oliveira et al. (2010) conceituam planejamento estratégico como os mecanismos para estabelecer metas, ações, tomar decisões, mobilizar recursos etc. (fluxograma 3):

RC: 101899

Disponível em: https://www.nucleodoconhecimento.com.br/contabilidade/assessoria$\underline{\text { contabil }}$ 
Fluxograma 3 - Conceito de planejamento estratégico

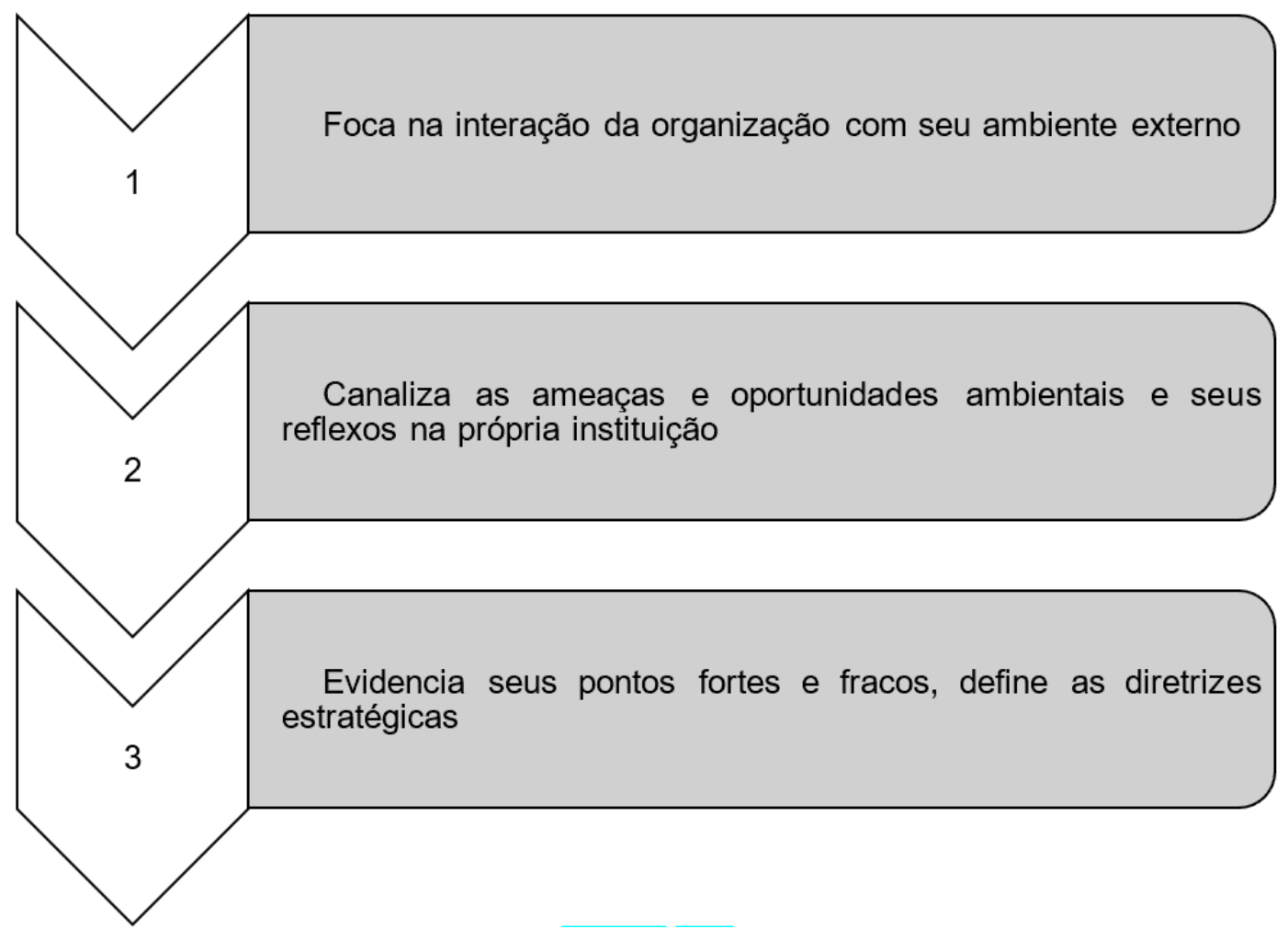

Adaptado de: Oliveira et al. (2010, p. 30).

Desse modo, o ato de planejar estrategicamente aumenta as possibilidades de êxito de uma organização. Assim, entende-se que o planejamento deve ser eficiente quanto aos cenários nele estabelecidos (BRUNO; GOMES, 2010).

\subsubsection{ORÇAMENTOS}

Entende-se que o orçamento é uma ferramenta de grande relevância no âmbito do setor público e privado, visto que ele é utilizado como forma de organização dos recursos financeiros (HADDAD; MOTA, 2010).

Para Moreira (2018), a organização precisa do orçamento para controlar o seu sistema e para o fornecimento dos números e avaliação dos resultados obtidos. Os orçamentos de uma organização estão ligados a um plano futuro de gestão de uma organização para um determinado período (BRUNI; GOMES, 2010).

RC: 101899

Disponível em: https://www.nucleodoconhecimento.com.br/contabilidade/assessoriacontabil 
Dessa forma, Haddad e Mota (2010) apresentam o processo orçamentário como inovador em se tratando do setor público. Isto a partir do surgimento do Plano Plurianual (PPA), da Lei de Diretrizes Orçamentárias (LDO) e do Orçamento Anual (LOA).

Para Araújo e Arruda (2009), esse ciclo orçamentário refere-se ao processo do orçamento e obtém transparência por meio da participação durante os processos. Destaca-se ainda que as singularidades referentes ao ciclo orçamentário ocorrem de forma temporal e de forma repetitiva, com semelhanças de períodos em períodos em uma organização.

Por fim, aponta-se que a Lei de Diretrizes Orçamentárias é caracterizada como um instrumento de planejamento relativo às diretrizes e às metas do governo. Logo, não leva em afeição os valores, o que o diferencia do plano plurianual (ÁVILA; BÄCHTOLD; VIEIRA, 2011).

\subsubsection{CONTROLE DE CUSTOS E DESPESAS}

Possuir crédito junto aos seus fornecedores é primordial dentro da organização, visto que ela depende de seus fornecedores para sobreviver no mercado. Além de cumprir com seus compromissos, tem-se a garantia de não efetuar um pagamento em duplicidade ou sem uma evidência documental (TROMBETTA, 2014).

Destaca-se ainda "que não há sentido falar em controle sem que os resultados realizados possam ser comparados a algo efetivamente desejável e expresso através dos planejamentos orçamentários de receitas, despesas e recursos" (BRUNI; GOMES, 2010, p. 94).

Logo, Trombetta (2014) ressalta a necessidade de controle de custos e despesas dentro de uma organização, seja ela pública ou privada, para que se possa possuir vantagens no mercado e estar sempre em dia com todos.

RC: 101899

Disponível em: https://www.nucleodoconhecimento.com.br/contabilidade/assessoria$\underline{\text { contabil }}$ 


\subsubsection{CONTROLE FINANCEIRO}

Segundo Baradel; Martins e Oliveira (2010), o controle financeiro de uma organização deve ser planejado e realizado a partir dos recursos existentes e das necessidades dela.

Para Sá (2009, p. 13 apud ARAÚJO; TEIXEIRA; LICÓRIO, 2015, p. 76), “o planejamento financeiro trata-se de um agrupamento de operações financeiras realizadas para alcançar um determinado objetivo."

Desse modo, Oliveira (2012) aponta que, com a inexistência de um método de confiança para a estimação de necessidades financeiras, uma organização pode não possuir recursos necessários para cumprir com os compromissos.

Salienta-se que este controle pode ser utilizado como um guia para a avaliação de todos os aspectos financeiros das organizações a partir de todos os processos organizacionais (LAVARDA; PEREIRA, 2010).

Em contrapartida, Oliveira (2012) aponta que não se deve confundir controle financeiro com investimentos, ou até mesmo esperar momentos de crise para tomar a iniciativa de fazer o planejamento e controle financeiro;

Um controle financeiro com boa estrutura é essencial para se obter êxito na gestão de uma organização e, para que se possa obter lucratividade, deve-se apresentar atenção máxima aos registros do caixa da organização (TROMBETTA, 2014).

\subsubsection{FLUXO DE CAIXA}

Conforme Marques (2013), o desenvolvimento do fluxo de caixa relaciona-se à organização adequada do sistema financeiro, que refere à movimentação cotidiana e influência no sistema empresarial de uma organização. 
Entende-se que "cabe ao administrador financeiro das empresas analisar o fluxo de caixa, o giro da empresa através das entradas e saídas" (SIGNORI, 2013).

Para Araújo; Teixeira e Licório (2015), planejar o fluxo de caixa é essencial e tem como objetivo principal o processo decisório de controle financeiro e da forma estratégica de uma organização.

Segundo Marin e Palmeira (2014), existem dois tipos de fluxos de caixa: o histórico e o projetado. O primeiro auxilia no planejamento futuro, por ser histórico. O segundo, objetiva a identificação de faltas e excessos.

Compreende-se que a distribuição do fluxo de caixa está totalmente relacionada com as saídas e entradas de capital circulante dentro de uma organização (OLIVEIRA, 2015).

A ferramenta do fluxo de caixa relaciona-se diretamente à entrada e à saída de capital, considerando o início contábil do regime de caixa de uma organização (BARADEL; MARTINS; OLIVEIRA, 2010).

Dessa forma, apresenta-se a necessidade de conhecer de forma antecipada as necessidades e saldos de caixa curto, médio e longo, pois esse conhecimento facilita a tomada de decisões dos gestores e administradores da empresa (MARIN; PALMEIRA, 2014).

Para Cunha; Martins e Assaf Neto (2014), o êxito do fluxo de caixa é projetado a partir das demonstrações de resultados dos balanços patrimoniais e, consequentemente, da atuação econômica da empresa e de seus valores estimados.

Compreende-se que o fluxo de caixa, em acordo com outros instrumentos de análise financeira, como os relatórios, balanço patrimonial etc., torna-se uma competente ferramenta de apoio para tomada de decisão (MARIN; PALMEIRA, 2014). 
Logo, é a partir do sistema de fluxo de caixa que se possibilita a formação de uma empresa ideal, com todas as suas objetividades (MARQUES, 2013). Destaca-se, ainda, que apresentar um capital de giro pode ser um fator determinante para que as metas sejam alcançadas e para o mantimento da organização no mercado (BARADEL; MARTINS; OLIVEIRA, 2010).

\subsubsection{CONTROLE DE CAPITAL DE GIRO}

Segundo Signori (2013), o capital de giro retrata o valor completo dos recursos financeiros existentes dentro de uma organização, que servem para o seu financiamento cíclico.

Ainda de acordo com Signori (2013), existem mecanismos que auxiliam no controle do capital de giro, como (fluxograma 4):

Fluxograma 4 - Controle do capital de giro de uma organização
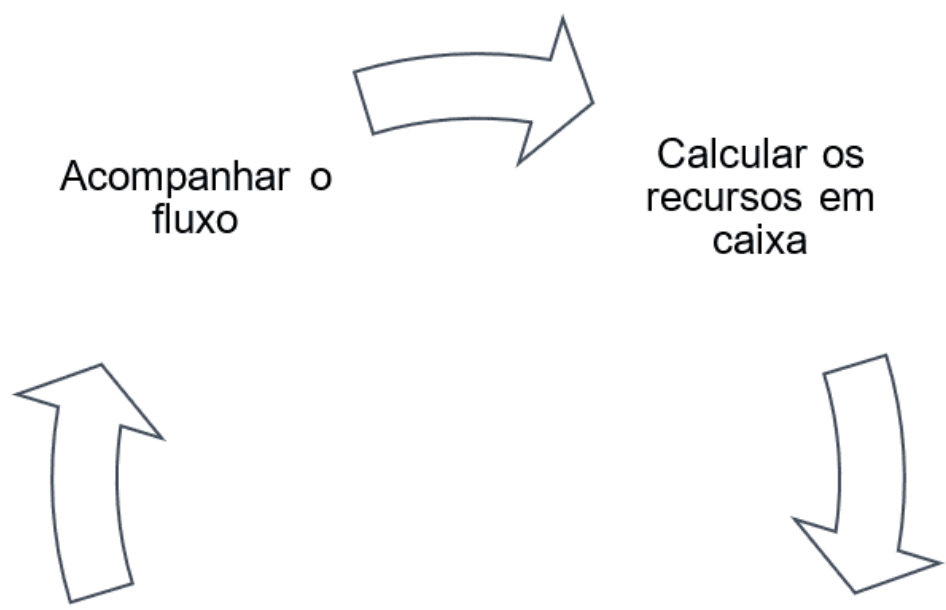

Investir recursos

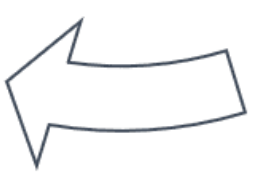

Antecipar recebíveis

Adaptado de: Signori (2013).

RC: 101899

Disponível em: https://www.nucleodoconhecimento.com.br/contabilidade/assessoria$\underline{\text { contabil }}$ 
Para que haja o cumprimento dos pagamentos nas datas corretas dentro uma organização, é essencial a existência de um capital de giro suficiente, ou seja, a organização necessita apresentar uma condição de liquidez (BARADEL; MARTINS; OLIVEIRA, 2010).

Com base em Oliveira (2015), nota-se que, para identificar o capital de circulação líquida ${ }_{2}$ é necessário que a empresa defina um capital circulante no momento final e deduza no momento de início, para estimação de ganhos e perdas e demais operações.

De acordo com Trombetta (2014), o ato de controlar o capital de giro de uma organização possibilita o acompanhamento e cumprimento das datas importantes para que os lucros sejam utilizados para pagamento de dívidas.

\section{MATERIAIS E MÉTODOS}

Os materiais e métodos são utilizados para verificar o conhecimento científico e estão relacionados à metodologia científica e ao detalhamento descritivo de como será executada uma pesquisa (GIL, 2019).

Destaca-se, ainda, que os materiais e métodos auxiliam no planejamento dos discentes de um curso superior, por meio do ato de compreender a real natureza da pesquisa e os seus objetivos a serem alcançados. Assim, por meio da classificação do método e do detalhamento do que será executado em uma pesquisa, é possibilitada a melhoria na qualidade e produtividade de trabalhos de cunho científico.

\subsection{PROCEDIMENTOS METODOLÓGICOS}

Os procedimentos metodológicos estão relacionados com o método científico de uma pesquisa. Eles são baseados em técnicas específicas e operacionais, a partir de etapas e técnicas bem definidas (PRAÇA, 2015). 
Desse modo, foi escolhida a natureza da pesquisa, que consiste em uma abordagem qualitativa. Em seguida, quanto aos seus fins, o estudo foi caracterizado como descritivo, por ter realizado uma descrição a respeito do tema. Por fim, foi realizada a escolha dos meios, que consistiu na pesquisa bibliográfica.

\subsubsection{QUANTO À NATUREZA}

A pesquisa é de natureza básica e foca na geração de conhecimentos da atualidade, sem aplicações práticas. É observada em artigos que disponham dados empíricos, obtidos por observação direta ou indireta do comportamento (STRAPASSON; MAGALHÃES; CUSTÓDIO, 2013).

Em consonância, destaca-se que pesquisas com essa natureza propiciam o enriquecimento de conhecimentos dos fenômenos e fatos da realidade social (LEÃO, 2016).

Deu-se preferência pela pesquisa de natureza básica porque esse tipo de pesquisa preocupa-se com a realidade das relações e com os fatos sociais atuais. Ela se dá a partir de pesquisas com foco na compreensão e descrição dos fatos, com base em conhecimentos de grande relevância, mas sem aplicação prática.

\subsubsection{QUANTO AOS FINS}

As pesquisas com finalidades descritivas buscam, de forma geral, a descrição de determinado fenômeno ou população, e uma de suas peculiaridades está na utilização de técnicas padronizadas de coleta de dados (GIL, 2017).

Salienta-se que essa pesquisa objetivou a descrição a partir de uma abrangência de características de uma situação, tema, indivíduo, grupo etc. registrando os fenômenos sem nenhum aprofundamento (PEDROSO; SILVA; SANTOS, 2017).

Foram identificadas as atribuições e a importância do profissional da área de contabilidade dentro de uma organização e foi verificada a situação atual da 
economia no país e ocorrência da prestação de serviços na área contábil, e, com base nisso, observou-se como a contabilidade está sendo aplicada nas áreas administrativa e financeira.

\subsubsection{QUANTO AOS MEIOS}

De acordo com Gil (2019), a pesquisa bibliográfica é importante, pois é desenvolvida com base em obras publicadas e disponibilizadas de forma virtual ou física.

Salienta-se que o principal objetivo deste tipo de pesquisa é a sua indicação final, a de proporcionar a revisão de abordagens, conceitos e categorias referente ao tema estudado (TREINTA et al., 2014).

Tendo em vista os fatos observados, compreendeu-se que a vantagem principal do procedimento de pesquisa bibliográfico foi o fato da pesquisa ter propiciado um leque de autores e obras como um instrumento de análise de abordagens e conceitos já existentes. Logo, essa escolha possibilitou aos pesquisadores a aquisição de uma vasta gama de conhecimentos sobre o tema investigado.

\section{CONSIDERAÇÕES FINAIS}

Diante do exposto, compreendeu-se que a assessoria contábil é de suma importância para uma organização em tempos de crise, visto que ela é uma ferramenta de gestão estratégica primordial que auxilia os gestores diante de todo o processo de planejar, gerenciar, executar, controlar e até mesmo na adoção de decisões para a manutenção de uma organização.

Notou-se que a assessoria contábil possibilita o conhecimento da situação empresarial e a tomada de decisões importantes pelo profissional da contabilidade diante de problemáticas, assim como também proporciona melhor controle do orçamento das contas a pagar e receber, o que auxilia na estabilização orçamentária e financeira de uma organização e minimiza os impactos da crise. 
Com relação ao problema de pesquisa: de que forma a assessoria contábil pode ser utilizada como uma ferramenta de gestão estratégica para as organizações em tempos de crise? Observou-se que, a partir da assessoria contábil, as empresas podem melhorar uma série de processos organizacionais, prevendo cenários e planejando ações interventivas, tornando mais fácil identificar oportunidades para gerenciar as crises.

Dessa forma, observou-se que a pesquisa foi de suma relevância para as discussões, reflexões e compreensões entre os futuros profissionais da área de Ciências Contábeis, acerca das modificações que ocorreram no setor econômico do Brasil nos últimos anos, bem como demonstrou a relevância da assessoria contábil para a gestão estratégica em tempos de crise.

\section{REFERÊNCIAS}

ARAÚJO, A.; TEIXEIRA, E. M.; LICÓRIO, C. A importância da gestão no planejamento de fluxo de caixa para o controle financeiro de micro e pequenas empresas. Redeca, v. 2, n. 2, p. 73-88, 2015. Disponível em: https://revistas.pucsp.br/redeca/article/view/28566. Acesso em: 18 ago. 2021.

ARRUDA, C. R. Atribuição da auditoria interna em tempos de crise econômica e financeira dentro das empresas. 2015. TCC (Especialização em Auditoria e Controladoria Empresarial) - Universidade Federal de Mato Grosso, Faculdade de Administração e Ciências Contábeis, Cuiabá, MT, 2017.

ÁVILA, C. A. de; BÄCHTOLD, C.; VIEIRA, S. de J. Noções de Contabilidade Pública. Curitiba: Instituto Federal de Educação, Ciência e Tecnologia. Educação a Distância. Escola Técnica Aberta do Brasil - e-Tec Brasil, 2011.

BARBOSA FILHO, F. de H. A crise econômica de 2014/2017. Estudos Avançados, v. 31, n. 89, p.51-60, 2017. Disponível em: https://www.scielo.br/j/ea/a/. Acesso em: 02 set. 2021. 
BECKER, A. C. V. Gestão empresarial. VIII JICEX - Jornada de Iniciação Científica e de Extensão Universitária, v. 8, n. 8, 2016. Disponível em: http://unisantacruz.edu.br/revistas/index.php/JICEX/article/view/1789. Acesso em: 04 set. 2021.

BERSELLI, C. SANTOS, G. de S. dos. O desafio da precificação em serviços turísticos em tempos de crise: um estudo de caso em Pelotas/RS. Revista Observatorio de la Economía Latinoamericana researchgate. v. 1, n. 1, p. 1-8, 2016. Disponível em: http://www.eumed.net/cursecon/ecolat/br/16/hoteleria.html. Acesso em: 30 mai. 2021.

BARADEL, E. C; MARTINS, S.; OLIVEIRA, A. R. Planejamento e controle financeiro: pesquisa-ação em uma microempresa varejista. Revista de Negócios, v. 15, n.4, p. 78-96, 2011. Disponível em: https://bu.furb.br/ojs/index.php/rn/article/view/1950/162. Acesso em: 04 set. 2021.

BRUNI, A. L.; GOMES, S. M. da S. Controladoria: conceitos, ferramentas e desafios. Salvador: EDUFBA, 2010.

CARVALHO, D. Orçamento e Contabilidade Pública. $5^{\text {a }}$ ed. Rio de Janeiro: Elsevier Editora Ltda, 2010

CARVALHO, L. O. R. et al. Metodologia científica: teoria e aplicação na educação a distância. Petrolina-PE: Universidade Federal do Vale do São Francisco, 2019.

CUNHA, M. F. da; MARTINS, E.;ASAFE NETO, A. Avaliação de empresas no Brasil pelo fluxo de caixa obtido: evidências empíricas sob o ponto de vista dos direcionadores de valor nas ofertas públicas de aquisições de ações. Revista de Administração. v. 49, n. 2, p. 251-266, 2014. Disponível em: https://www.sciencedirect.com/science/article/pii/S0080210716303442. Acesso em: 30 ago. 2021. 
CREPALDI, S. A. Contabilidade tributária: teoria e prática. São Paulo: Saraiva, 2014.

DAFT, R. L. Organizações: teoria e projetos. $11^{\mathrm{a}}$ ed. São Paulo: Cengage Learning, 2014.

FELIPE, J. M. A prestação de serviços contábeis em tempos de crise econômica: uma pesquisa no município de Criciúma - SC. 2017. Trabalho de Conclusão de Curso (Bacharel em Ciências Contábeis) - Universidade do Extremo Sul Catarinense, UNESC, Criciúma, SC, 2017.

GARRISON, R. H.; NOREEN, E. W.; BREWER, P. C. Contabilidade gerencial. 14 ed. Porto Alegre: AMGH Editora, 2013.

GIARETTA, C. C et al. Contabilidade fiscal/tributária. Anais Enaproc, v. 1 n. 1, 2020. Disponível em: https://periodicos.uniuv.edu.br/enaproc/article/view/722. Acesso em: 01 set. 2021.

GIL, A. C. Como elaborar projetos de pesquisa. 6ª ed. São Paulo: Atlas, 2017.

GIL, A. C. Métodos e técnicas de pesquisa social. 7ª̣ ed. São Paulo: Atlas, 2019.

GONÇALVES, J. R. Como escrever um artigo de revisão de literatura. Revista JRG de Estudos Acadêmicos, [S. I.], v. 2, n. 5, p. 29-55, 2015. Disponível em: http://www.revistajrg.com/index.php/jrg/article/view/122. Acesso em: 06 set. 2021.

HADDAD, R. C.; MOTA, F. G. Lima. Contabilidade pública. Florianópolis: Departamento de Ciências da Administração, UFSC; Brasília: CAPES: UAB, 2010.

LAVARDA, C. E. F.; PEREIRA, A. M. Planejamento e Controle orçamentário empresarial como Ferramenta de Apoio à Tomada de Decisão. ABCustos, São Leopoldo: Associação Brasileira de Custos, v. 6, n. 1, p. 40-58, 2010. Disponível em: https://revista.abcustos.org.br/abcustos/article/view/121/604. Acesso em: 02 set. 2021.

RC: 101899

Disponível em: https://www.nucleodoconhecimento.com.br/contabilidade/assessoriacontabil 
LEÃO, L. M. Metodologia do estudo e pesquisa: facilitando a vida dos estudantes, professores e pesquisadores. Petrópolis: Vozes, 2017.

MARIN, F.; PALMEIRA, E. M. A importância da gestão do fluxo de caixa. Contribuciones a la Economía, n. 2014-0, 2014. Disponível em: https://bit.ly/2IAmDzq. Acesso em: 13 ago. 2021.

MARQUES, W. L. Controlando as finanças utilizando fluxo de caixa. São Paulo: Saraiva, 2013.

MAZZIONI, S. As estratégias utilizadas no processo de ensino-aprendizagem: concepções de alunos e professores de ciências contábeis. Revista Eletrônica de Administração e Turismo - REAT, v. 2, n. 1, p. 93-109, 2013.

MOREIRA, W. V. A aplicação da controladoria no processo de gestão empresarial na área financeira. Faculdade UniEvangelica. Curso de Ciências Contábeis. Anápolis/GO. $2018 . \quad$ Disponível em> http://repositorio.aee.edu.br/bitstream/aee/8239/1. Acesso em: 13 ago. 2021.

OLIVEIRA, L. M. et al. Controladoria Estratégica. 6ª ed. São Paulo: Atlas, 2010.

OLIVEIRA, D. C. A importância do planejamento financeiro. Revista Intellectus. Ano VIII, n. 20, p. 75-83, 2012. Disponível em: http://www.revistaintellectus.com.br/artigos/20.210. Acesso em: 13 ago. 2021.

OLIVEIRA, R. A. L. de. Gestão de capital de giro: controle das necessidades de caixa. In: XI Congresso Nacional De Excelência Em Gestão, 2015. Disponível em: novarse.org/sites/default/files/T_15_058M. Acesso em: 20 ago. 2021.

PADOVEZE, C. L. Contabilidade Gerencial. Curitiba: IESDE Brasil S.A, 2012. $376 p$.

PEDROSO, J. de S.; SILVA, K. S. da; SANTOS, L. P. dos. Pesquisa descritiva e pesquisa prescritiva. JICEX, v. 9, n. 9, 2017. Disponível em: 
http://unisantacruz.edu.br/revistas/index.php/JICEX/article/view/2604. Acesso em: 25 ago. 2021.

PENTEADO, R. F. et al. A colaboração na evolução histórica da gestão empresarial. Revista Eletrônica Fafit/Facic, v. 3, n. 1, 2012. Disponível em: http://www.fafit.com.br/revista/index.php/fafit/article/view/38. Acesso em: 02 set. 2021.

PRAÇA, F. S. G. Metodologia da pesquisa científica: organização estrutural e os desafios para redigir o trabalho de conclusão. Revista Eletrônica Diálogos Acadêmicos, v. 8, n. 1, p. 72-87, 2015. Disponível em: http://www.uniesp. edu.br/fnsa/revista. Acesso em: 25 ago. 2021.

RODRIGUES, A. R. de A. A contabilidade financeira e o seu papel ao serviço da fiscalidade empresarial: estudo de caso para a empresa "LS". 2015. Dissertação (Mestrado em Contabilidade) - Universidade de Lisboa, Instituto Superior de Economia e Gestão, Lisboa, Portugal, 2015.

RUSCHEL, M. E.; FREZZA, R.; UTZIG, M. J. S. 0 impacto do SPED na Contabilidade: desafios e perspectivas do profissional contábil. Revista Catarinense Da Ciência Contábil, v. 10, n. 29, p. 09, 2019. Disponível em: https://revista.crcsc.org.br/index.php/CRCSC/article/view/1215. Acesso em: 02 jun. 2021.

SALIM, J. J.; OLIVEIRA, A. E. M. Contabilidade financeira. Rio de Janeiro: FGV Editora, 2019.

SANTOS, C. B.; ALMEIDA, K. K. N. Análise introdutória das mudanças provocadas na contabilidade pública pelas normas brasileiras de contabilidade aplicadas ao setor público. Revista de Administração, Contabilidade e Sustentabilidade - REUNIR. v. 2, n. 1, p. 21-38, 2012. Disponível em: https://reunir.revistas.ufcg.edu.br/index.php/uacc/article/view/40. Acesso em: 18 ago. 2021.

RC: 101899

Disponível em: https://www.nucleodoconhecimento.com.br/contabilidade/assessoria$\underline{\text { contabil }}$ 
SANTOS, M. L. dos; SOUZA, M. A. de. A importância do profissional contábil na contabilidade gerencial: uma percepção dos conselheiros do CRC/MG. E-civitas Revista Científica do Departamento de Ciências Jurídicas, Políticas e Gerenciais do UNI-BH Belo Horizonte, vol. III, n. 1, jul-2010. ISSN: 1984-2716. Disponível em: www.unibh.br/revistas/ecivitas/ Acesso em: 27 mai. 2021.

SCHULTZ, G. Introdução à gestão de organizações. Porto Alegre: Editora da UFRGS, 2016. 159p.

SIGNORI, B. C. Identificação de Linhas de Crédito disponíveis para o Empreendedor Individual nas Instituições Financeiras do Estado de Santa Catarina. 2013. Trabalho de Conclusão de Curso (Especialização em Gestão Contábil e Financeira) - Universidade Tecnológica Federal do Paraná, Pato Branco, PR, 2013.

SOUZA, R. S. de. A condição organizacional: o sentido das organizações no desenvolvimento rural. Santa Maria: Ed. da UFSM, 2012.

STRAPASSON, B. A.; MAGALHÃES, F. G.; CUSTÓDIO, J. K. Comunicação Entre a Pesquisa Básica, Aplicada e Teórica na Análise do Comportamento no Brasil: Uma Análise Bibliométrica. Interação em Psicologia: Curitiba, v. 17, n. 1, p. 117128 jan./abr. 2013.

Disponível em: https://revistas.ufpr.br/psicologia/article/view/26496/21326. Acesso em: 03 set. 2021.

TONELO, I. O conceito de crise em Marx e a época imperialista. 2014. Dissertação (Mestrado) - Universidade Estadual de Campinas, Instituto de Filosofia e Ciências Humanas, Campinas, SP, 2014.

TREINTA, F. T. et al. Metodologia de pesquisa bibliográfica com a utilização de método multicritério de apoio à decisão. Production, v.3, n. 24, p. 508-520, 2014. Disponível em: https://doi.org/10.1590/S0103-65132013005000078. Acesso em: 24 ago. 2021. 
TROMBETTA, A. A importância do controle financeiro nas empresas. 2014. $41 \mathrm{f}$. Trabalho de Conclusão de Curso (Especialização) - Universidade Tecnológica Federal do Paraná, Pato Branco, PR, 2014.

VIEIRA, F. S. Crise econômica, austeridade fiscal e saúde: que lições podem ser aprendidas? Nota Técnica 26. Brasília, agosto de 2016. Disponível em: http://www.ipea.gov.br. Acesso em: 01 set. 2021.

XAVIER, T. L. S. Gestão Empresarial. Caderno elaborado pelo Instituto Federal Sul-Rio-Grandense, Campus Pelotas - Agrotécnico Visconde da Graça (CAVG) para a Rede e-Tec Brasil, do Ministério da Educação em parceria com a Universidade Federal do Mato Grosso. Cuiabá: UFMT, 2015.

Enviado: Outubro, 2021.

Aprovado: Novembro, 2021. 